\title{
CARACTERIZAÇÃO DO REGIME PLUVIOMÉTRICO DA REGIÃO DO PROJETO RIO FORMOSO NA BACIA DO ARAGUAIA, TO., BRASIL
}

\author{
Jair da Costa OLIVEIRA FILHO', Eder Soares PINTO', Luciano Marcelo Fallé \\ SABOYA ${ }^{1}$, Antonio José PERON ${ }^{1}$, Gaspar F. CAETANO ${ }^{2}$
}

\begin{abstract}
RESUMO - A caracterização do regime pluviométrico é fundamental para a tomada de decisão junto às práticas agrícolas para a safra e entresafra, no município de Formoso do Araguaia - TO. Foram obtidos dados diários de precipitação pluviométrica no período de 1981 a 1997, excluídos os anos de 1991, 1992 e 1993, totalizando 14 anos de observações. Os dados foram analisados via sistemas ANFLPLUVIE.EXE e Chuva (Assad et al, 1994). Analisou-se as precipitaçōes médias anuais e mensais; as freqüências mensais, quinzenais e decendiais em $20 \%, 50 \%$ e $80 \%$ de probabilidade de ocorrência e a quantificação e freqüência dos veranicos. A precipitação média anual foi de $1.675,7 \mathrm{~mm}$; e a precipitação média mensal do período chuvoso foi maior em dezembro $(330,9 \mathrm{~mm})$ e menor em abril $(109,3 \mathrm{~mm}), 95,16 \%$ das chuvas na região ocorreram entre os meses de outubro a abril; em $85,71 \%$ dos anos observados, o índice pluviométrico foi superior a $1.000 \mathrm{~mm}$ anuais.
\end{abstract}

Palavras-chave: Precipitação, Veranicos

Characterization of Rainfall Patterns in the Projeto Rio Formoso Region in the Araguaia Basin, Tocantins State, Brazil

ABSTRACT - The characterization of rainfall patterns is fundamental for deciding farming practices both for the high production and low production periods, in Formoso do Araguaia, State of Tocantins, Brazil. Daily rainfall data were obtained in the period 1981-1997, excluding the years 1991, 1992 and 1993, totaling 14 years of observation. These data have been analyzed using the ANFLPLUVIE.EXE and Chuva systems (Assad et. al. 1994). The yearly and monthly rainfall means were analyzed; with a frequency in time intervals of 30,15 and 10 days with a probability of occurrence of 20,50 , and $80 \%$, and so the frequency of dry days as well. The mean annual rainfall was $1,675.7 \mathrm{~mm}$; the highest monthly mean rainfall occurring in December $(330.0 \mathrm{~mm})$ and the lowest in April $(109.3 \mathrm{~mm})$. Most of the rain in the region $(95.16 \%)$ occurred from October to December. In $85.71 \%$ of the observed years-annual rainfall value were above $1,000 \mathrm{~mm}$.

Key-words: precipitation, dry days

\section{INTRODUÇÃO}

As áreas agrícolas irrigadas e de sequeiro do Tocantins dependem da homogeneidade de ocorrência da precipitação pluviométrica e do acúmulo de água em reservatórios e posterior utilização ou da precipitação direta sobre a cultura.

O clima no Sul do Estado do Tocantins é caracterizado pela presença predominante de duas massas de ar que atuam na região, a Massa Equatorial Continental, com movimentos convectivos do ar na atmosfera, quente e úmida, e centro

\footnotetext{
'Fundação Universidade do Tocantins - UNITINS, Campus de Gurupi - Cx Postal 66 - 77400-000 -Gurupi-TO.
}

${ }^{2}$ CODETINS/Formoso do Araguaia 
de baixa pressão e a Massa Tropical Marítima, que está associada ao movimento descendente do ar na atmosfera, que sofre aquecimento adiabático e a torna uma massa quente e seca, desprovida de nebulosidade e ausência de precipitação, e centro de alta pressão, Tubelis e Nascimento (1992).

Na região Sul do Estado do Tocantins, o período de seca ocorre de maio a setembro e o chuvoso de outubro a abril. A análise e caracterização desse regime pluviométrico é de fundamental importância para a tomada de decisão junto às práticas agrícolas (preparo de solo, plantio, tratos fitossanitários e colheita) a serem adotadas na área do Projeto do Rio Formoso.

Os trabalhos mais recentes que abordam a precipitação pluviométrica na região são de Assad et al. (1994); Meireles et al. (1996) e Oliveira Filho (1996).

\section{MATERIAL E MÉTODOS}

Para o desenvolvimento do trabalho foram obtidos dados diários de precipitação pluviométrica no período de 1981 a 1997, suprimidos os anos de 1991, 1992 e 1993, devido à ausência de dados completos necessários para os modelos de análise utilizados, resultando uma série histórica de 14 anos, para a estação climatológica do "Projeto Rio Formoso", com as seguintes coordenadas geográficas: $12^{\circ} 02^{\prime} 00^{\prime \prime}$ latitude sul, $49^{\circ} 43^{\prime} 00^{\prime \prime}$ longitude oeste e altitude de $215 \mathrm{~m}$, localizada no município de Formoso do Araguaia, na região sul do estado do Tocantins.

A precipitação média anual foi calculada pela soma da precipitação para cada ano observado, dividido pelo número de anos observados. Esta metodologia também foi aplicada no cálculo das precipitações médias mensais.

A análise freqüêncial foi baseada nos decis superior, médio e inferior, assim distribuídos: Freqüência de 20\% (aparição de dois anos em cada dez anos), ou seja, $20 \%$ de valores observados são inferiores ao valor calculado; Freqüência de $50 \%$ (aparição de cinco anos, em cada dez anos), ou seja, $50 \%$ de valores observados são inferiores ao valor calculado; Freqüência de $80 \%$ (aparição de oito anos em cada dez anos), ou seja, $80 \%$ de valores observados são inferiores ao valor calculado, segundo metodologia adotada por Assad (1991).

Para determinação da ocorrência de veranicos, foram fixados períodos de análise de $05,10,15,20,25,30$ e 35 dias consecutivos sem chuvas nos meses de outubro a abril (período chuvoso), através do "software" ANFPLUVIE.EXE, que contabilizou dentro da freqüência de dias e no periodo desejado EMBRAPA.CERRADOS.

\section{RESULTADOS E DISCUSSÃO}

A precipitação média anual foi de $1675,7 \mathrm{~mm}$. Constatou-se que em $85,71 \%$ dos anos, o indice 
pluviométrico foi superior a $1000 \mathrm{~mm}$ anuais. Com relação à precipitação média mensal no período chuvoso, podemos observar que o mês de dezembro apresentou um maior valor, destacando-se dos demais com uma precipitação de $330,9 \mathrm{~mm}$ e o de menor valor foi do mês de abril com $109,3 \mathrm{~mm}$. A concentração do período chuvoso ocorreu nos meses de outubro a abril, tendo como os meses mais chuvosos dezembro, janeiro e março, como é observado na Figura 1. A concentração das chuvas na região aconteceu entre os meses de outubro e abril, correspondendo a $95,16 \%$ das ocorrências de chuva do período. Com relação ao período de seca, podemos observar que o mesmo ocorre de maio a setembro, apresentando os meses de junho, julho e agosto crítico, com precipitação próxima de zero.

As análises pluviométricas das freqüências mensais, quinzenais e decendiais em $20 \%, 50 \%$ e $80 \%$ de probabilidade de ocorrência, para a região de estudo podem ser tipificada da seguinte forma: destacou-se a redução de freqüência de precipitação a partir da $2^{\text {a }}$ quinzena de dezembro até a $2^{a}$ quinzena de fevereiro. Observou-se uma elevação na $1^{\mathrm{a}}$ e $2^{\mathrm{a}}$ quinzena de março e, posteriormente, uma nova redução até a entrada do período seco ( Figs 2, 3 e 4).

Com relação aos veranicos foram avaliados $05,10,15,20,25,30 \mathrm{e}$ 35 dias sucessivos sem chuvas nos meses de outubro a abril. Em outubro observou-se 86 veranicos de 05 dias,

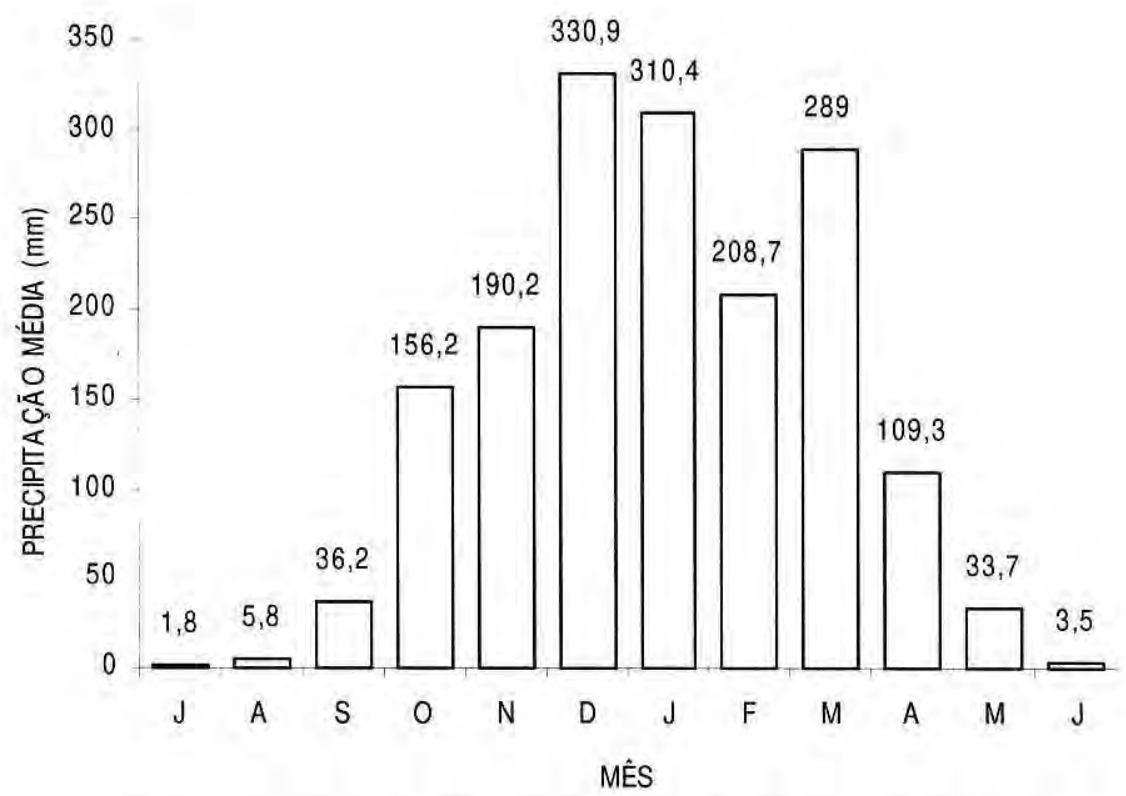

Figura 1. Altura pluviométricas médias na estação do Projeto Rio Formoso, Formoso do Araguaia - TO. 
11 de 10 e 01 de 15 dias; novembro janeiro 82, veranicos de 05 dias e 02 78 veranicos de 05 dias, 08 de 10 e 02 de 10 dias; fevereiro 87 veranicos de de 15 dias; dezembro 86 veranicos de 05 dias, 04 de 10 e 03 de 15 dias; 05 dias, 01 de 10 e 01 de 15 dias; março 89 veranicos de 05 dias e 02 de

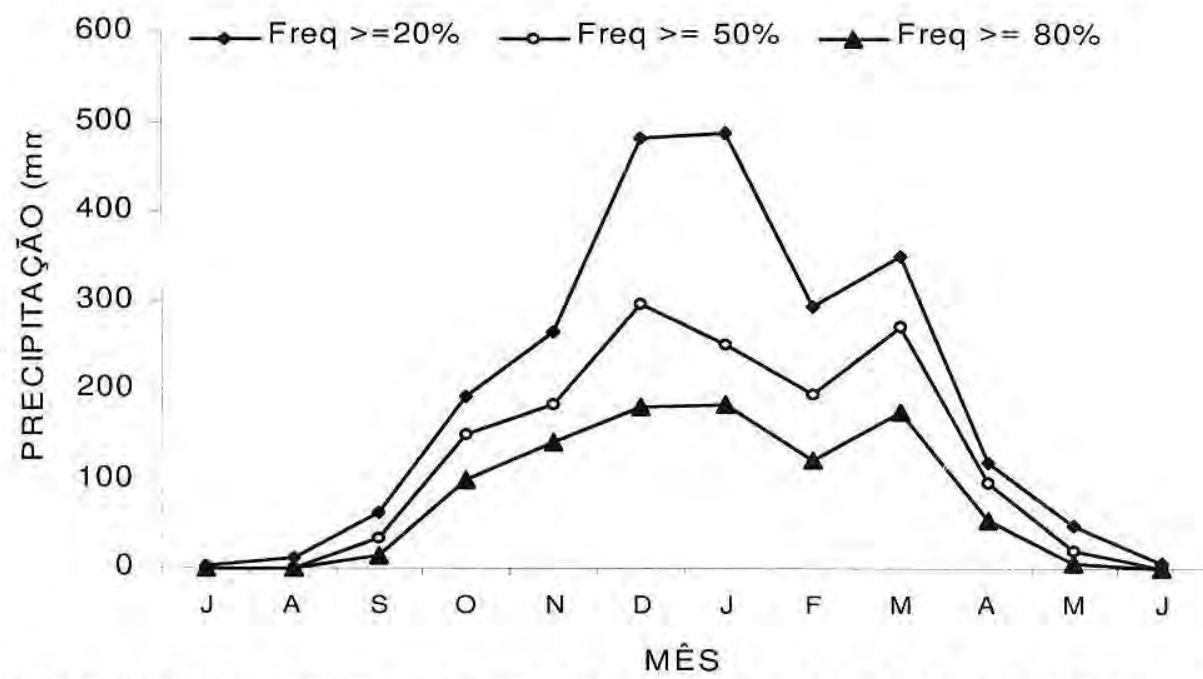

Figura 2. Análise freqüencial da precipitação para o período de 30 dias, Formoso do Araguaia-TO.

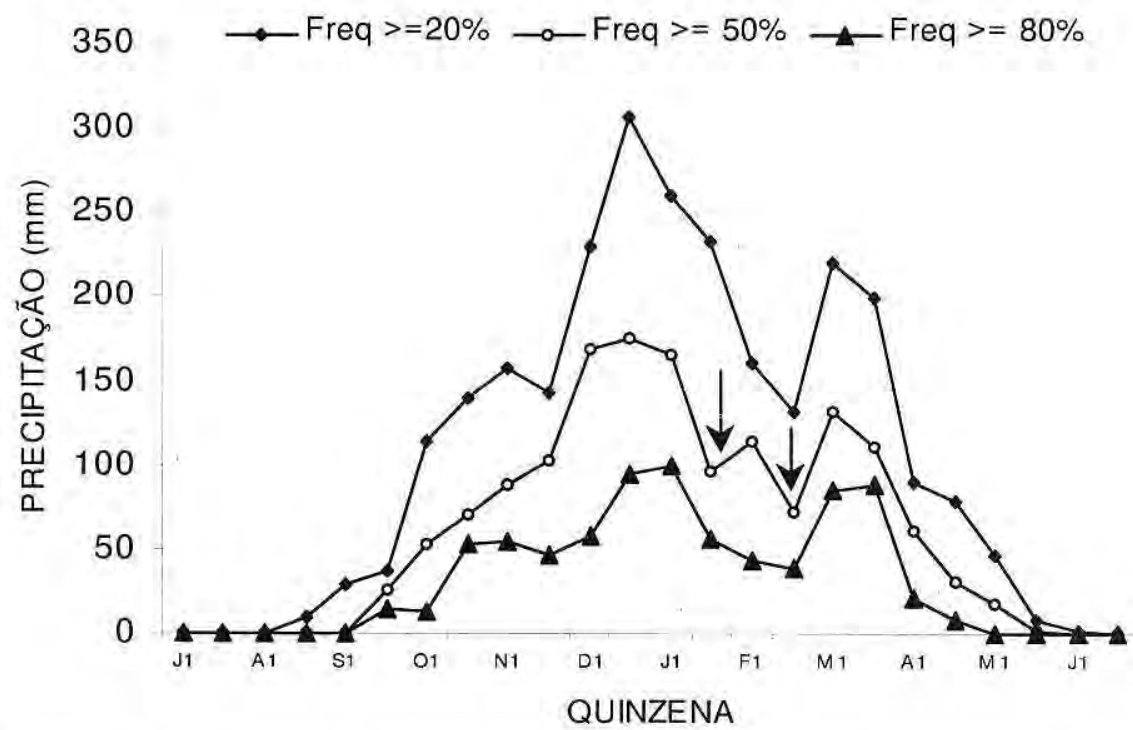

Figura 3. Análise freqüencial da precipitação para período de 15 dias, Formoso do Araguaia -TO. 


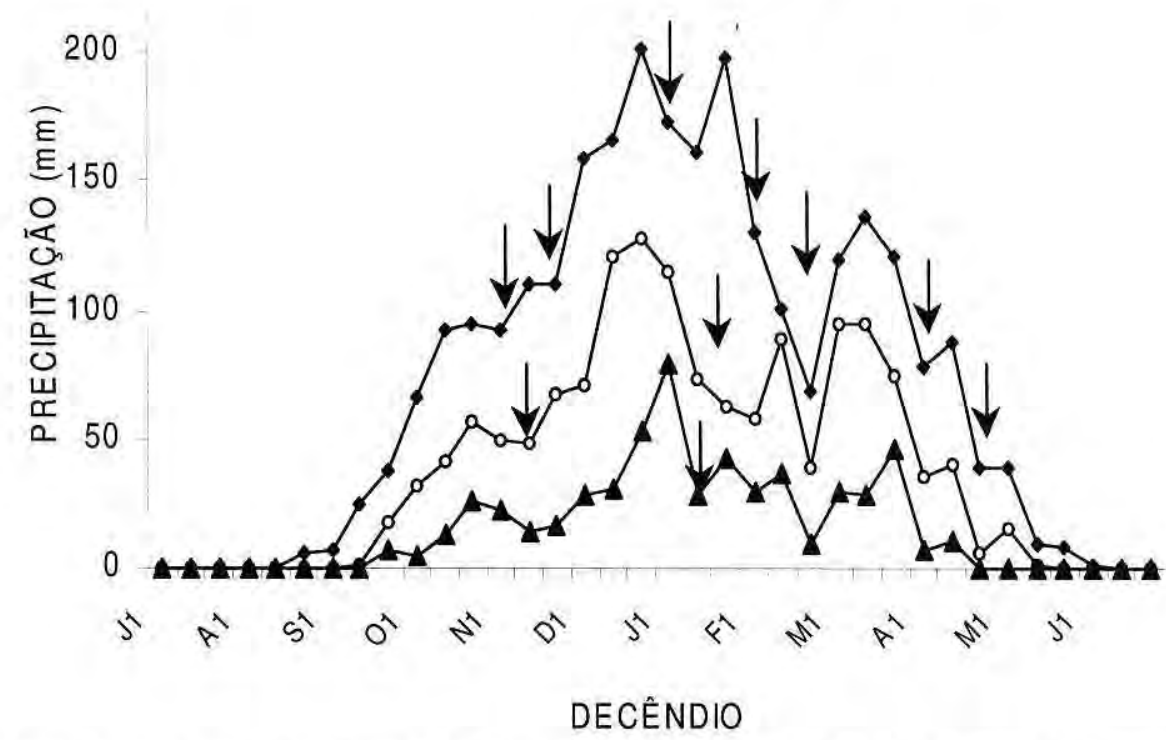

Figura 4. Análise freqüencial da precipitação para o período de 10 dias, Formoso do Araguaia - TO.

10 dias; abril 55 veranicos de 05,11 de 10,03 de 15 e 02 de 20 dias.

\section{CONCLUSÕES}

1. Na região em estudo, podemos observar a definição das estações de seca que ocorre no período de maio a setembro, e a de chuvas no período de outubro a abril.

2. A média anual de precipitação foi superior a $1600 \mathrm{~mm}$.

3. A média mensal dos meses chuvosos (outubro a abril) foi de $223,39 \mathrm{~mm}$

4. A média mensal nos meses secos (maio a setembro) foram próximas de zero.

5. As freqüências de $20 \%, 50 \%$ e $80 \%$ permitem analisar o comportamento e distribuição das precipitações nos meses chuvosos.

6. Os períodos de veranicos analisados de $05,10,15,20,25,30 \mathrm{e}$ 35 dias permitem concluir que da $2^{\text {a }}$ quinzena de dezembro até a $1^{\text {a }}$ quinzena de fevereiro ocorreu uma concentração de veranicos.

\section{Bibliografia citada}

Assad, E. D.; Evangelista, B. A. Análise freqüencial da precipitação Pluviométrica. In: ASSAD, E. D. et al., CHUVA NOS CERRADOS ANÁLISE E ESPACIALIZAÇÃO. Brasília: EMBRAPA-SPI, 1994. Cap. II, p. 25-41.

Meireles, E. J. L.; Silva, S. C. da.; Assad, E. D.; Lobato, E. J. V.; Bezerra, kkH. da. S.; Evangelista, B. A.; Moreira, L.; Cunha, M. A. C. da. Zoneamento agroclimático para 
arroz de sequeiro no Estado do Tocantins. Goiânia: EMBRAPA-CNPAF-APA, 1995.

18p. (EMBRAPA - CNPAF. kkDocumentos,158).

OLIVEIRA - FILHO, J. da C.; ARAÚJO, I. B.

Determinação da precipitação para o

Municipio de Formoso do Araguaia-TO.

Palmas: I Congresso Cientifico da

Universidade do Tocantins, 1996, p. 218. 